\title{
A prospective study on quality of life in youths after pectus excavatum correction
}

\author{
Johanne Jeppesen Lomholt ${ }^{1}$, Elisabeth Brammer Jacobsen ${ }^{2}$, Mikael Thastum ${ }^{1}$, Hans Pilegaard ${ }^{3,4}$ \\ ${ }^{1}$ Department of Psychology and Behavioural Sciences, Aarhus University, Aarhus, Denmark; ${ }^{2}$ Diploma in Health Science Program and Bachelor \\ of Science in Nursing Program, Denmark; ${ }^{3}$ Department of Cardiothoracic and Vascular Surgery, Aarhus University Hospital, Aarhus, Denmark; \\ ${ }^{4}$ Institute of Clinical Medicine, Aarhus University, Aarhus, Denmark \\ Correspondence to: Johanne Jeppesen Lomholt. Department of Psychology and Behavioural Sciences, Aarhus University, Bartholins Allé 9, 8000 \\ Aarhus C, Denmark. Email: johanhj@psy.au.dk.
}

\begin{abstract}
Background: The impact of correction of pectus excavatum (PE) on adolescents' health-related quality of life (HRQL) has only been investigated in prospective designs using disease-specific measures and without controls. The aim of this prospective study was to evaluate the HRQL before and after surgical correction of PE using a generic HRQL measure, and to compare the reported level of HRQL before surgery with an age-comparable control group.

Methods: Patients ( $n=107)$ and one of their parents $(n=106)$ completed the generic HRQL measure: the Child Health Questionnaire before, 3 months, and 6 months after correction for PE. A control group ( $\mathrm{n}=183)$ consisting of school children comparable in age completed the same measure on one occasion.

Results: The patients' level of HRQL before surgery was comparable to the level of the controls except for physical functioning; here boys reported impaired function compared to controls $(\mathrm{P}<0.0001, \mathrm{~d}=0.72)$. Both patients and parents reported improved emotional wellbeing and self-esteem, as well as an increase in physical and social activities from pre- to post-surgery. These improvements were statistically significant $(\mathrm{P} \leq 0.001-0.03)$ and yielded moderate to high effect sizes $\left(\eta^{2}=0.04-0.22\right)$.

Conclusions: The improvement of physical and psychosocial HRQL reported by both patients and their parents as proxy indicates the psychological implications of the deformity. Patients reported impaired physical function compared to controls. Further, pre-surgery differences in HRQL between the patients and the controls were lacking. However, the improvement in the patients' HRQL following surgery may justify the correction of pectus excavatum. The effect of the deformity on patients wellbeing compared with controls' needs to be addressed in further studies.
\end{abstract}

Keywords: Pectus excavatum; health-related quality of life; youths; Nuss procedure; prospective design

Submitted Feb 29, 2016. Accepted for publication Jul 12, 2016.

doi: $10.21037 /$ acs.2016.08.02

View this article at: http://dx.doi.org/10.21037/acs.2016.08.02

\section{Introduction}

Pectus excavatum (PE), or funnel chest, is the most common anterior chest wall deformity. It occurs in about one per 3-400 living born males and predominantly affects boys, with a 3-4:1 male dominance. The degree of the deformity varies among patients, but the majority of patients complain of the poor cosmetic appearance caused by the deformed sternum $(1,2)$. PE may also impair restrict chest wall movement and impair cardiorespiratory function (3-5). Patients report symptoms related to the deformity as exercise intolerance, shortness of breath, and weakness $(2,6,7)$. Previously, it has been stated that the deformity did not cause physiological dysfunction $(1,2)$.

However, recent studies have refuted this statement and shown physiological improvement after surgical correction in the form of improved cardiac function (8-10), chest wall motion (11), and lung function (12). Nonetheless, cosmetic 
complaints are still the main indication for patients to undergo correction (13).

Several studies have shown a positive effect on patients' wellbeing after surgery, represented by an increase in selfconfidence, self-esteem and involvement in social activities (14-17). Improvement in physical symptoms, increased body image satisfaction, and decreased negative feelings, such as frustration, sadness, and negative social experiences, have been reported in studies, which have all utilized a prospective design and PE-specific measures (15,18-21). In general, disease-specific measures focus on those dimensions that are likely to be affected by a treatment and are more sensitive to treatment-related changes. However, the use of disease-specific measures does not allow a comparison between healthy controls and patients $(22,23)$. Two studies have included generic HRQL measures to examine the generic HRQL in patients $1-1.5$ years after surgery compared to controls or norm data. These studies showed mixed results with regard to HRQL after surgery, and the impact of the correction of the deformed chest on the patients' HRQL was not clarified as the studies were not prospective in design $(17,24)$.

The aim of this prospective study was primarily to evaluate the HRQL before and after surgical correction of $\mathrm{PE}$ using a generic HRQL measure. Based on previous research, the hypotheses were that patients would experience an increase in social activities and physical functioning as well as an improvement of self-esteem and emotional wellbeing. Secondly, the aim was to investigate the patients' pre-surgery level of HRQL by comparing their pre-surgery reported level of HRQL with an age-comparable control group.

\section{Methods}

\section{Intervention group}

The patients were included in the intervention group consecutively. From 2006 to 2008, all children and adolescents who underwent $\mathrm{PE}$ correction through a modified Nuss procedure $(25,26)$ at Aarhus University Hospital and one of their parents were invited to participate in the study. Exclusion criteria were pre-existing chronic diseases and cognitive deficits. Five patients were excluded because of comorbidities (learning difficulties, Asperger syndrome, and heart failure).

None of the invited patients had their bar(s) removed during the study period and the same surgeon conducted

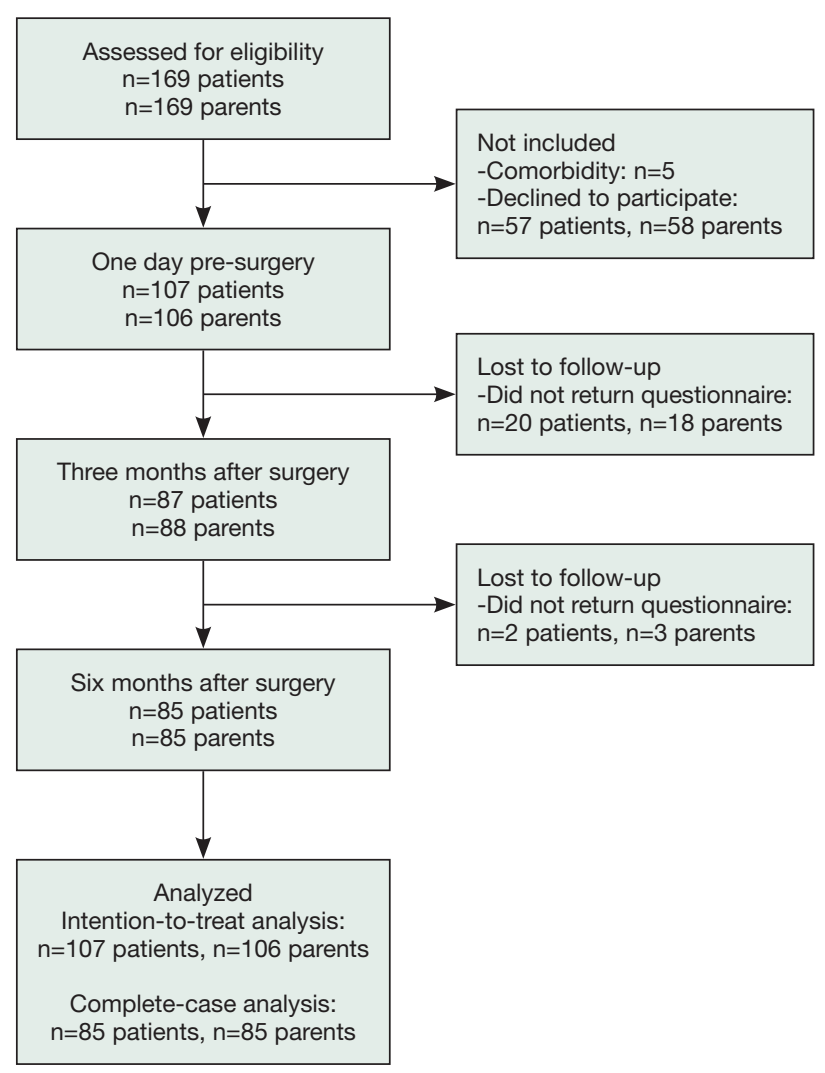

Figure 1 Selection of the intervention group.

all the surgeries. One hundred and seven patients and their parents agreed to participate in the study by completing questionnaires on three occasions: the day before surgery, and 3 and 6 months after surgery. As shown in Figure 1, 85 patients and parents completed the questionnaires at all three assessment points.

\section{Control group}

The control group consisted of 183 children and adolescents from one elementary school and two secondary schools. Schools rated in the municipality as average schools in regards to the children's socioeconomic status were selected. All children at the schools from $4^{\text {th }}$ to $12^{\text {th }}$ grade were invited to participate and there were no exclusion criteria enforced for the control group. To match the intervention group, boys aged between 11 and 20 years, and girls aged between 11 and 16 years were included. The control group completed the questionnaire on one occasion in 2007-2008, and the testing took place in the classrooms. Two research assistants administered the questionnaires in 
accordance with a test protocol. The control group data is based on a control sample presented in a previous paper (17).

\section{Ethical consideration}

The Ethical Review Board in Central Denmark Region was consulted. According to the regulations of the Ethical Review Board, questionnaire-based studies do not have to be registered. The project was registered at the Danish Data Protection Agency.

For all participants, written informed consent was obtained from both parents regarding participation of child/ adolescent and one from the participating parent.

\section{Measure}

\section{Child bealth questionnaire}

The Child Health Questionnaire (CHQ) is a multi-dimensional generic self-administered measure of HRQL (27). Table 1 shows the CHQ-CF87 (children form), which consists of 10 multi-item scales and 4 single-item scales, and the CHQPF50 (parent form), which consists of 11 multi-item scales and 4 single-item scales. The raw scale score was calculated by computing the mean of the items for each subscale. Scores for each subscale and single items were transformed on a scale from 0 (worst health) to 100 (best health) (except for the "Change in Health" scale which ranges from 1-5).

The validity and reliability of the CHQ have been shown to be acceptable in different samples (28-31), including Danish populations $(17,32)$. In this study, the Cronbach's alpha internal consistency reliability coefficient was acceptable for the multi-item scales from the CHQ-CF87 (Cronbach's alpha $=0.66-0.95$ ) and for the multi-item scales from the CHQ-PF50 (Cronbach's alpha $=0.62-1.00$ ), except for the behavior scale from the CHQ-PF50 at both baseline and 3 months follow-up (Cronbach's alpha $=0.38$ and 0.52 , respectively) and the family activities scale at 6 months follow-up from the CHQ-PF50 (Cronbach's alpha $=0.57$ ).

\section{Statistical analysis}

All statistical analyses were performed using IBM SPSS version 21.0 for Windows (IBM® SPSS $®$, IBM Corp., Armonk, New York). The alpha level was set at 0.05 for all analyses. In cases of multiple comparisons, Bonferroni corrections were applied to alpha levels in the main analysis. For the CHQ, the substitution of the missing items and the calculation of scores were performed according to the manual of the CHQ (27). The distribution of all data was analyzed using the Kolmogorov-Smirnov test, which showed that the CHQ scales were non-normally distributed. Associations between patient and parent scores were calculated using Spearman's Rank Order Correlation. Differences between the control and intervention group were analyzed using the chi-square test for categorical variables and Mann-Whitney $U$ test for continuous variables. Cohen's $d$ represents the effect size estimates and was calculated by dividing the mean difference by a pooled standard deviation. A $d$ was categorized as $0.2=$ small effect, $0.5=$ moderate effect, and $0.8=$ large effect (33). Because of the robustness of the ANOVA to departures from normality, a one-way repeated measures ANOVA was conducted to compare scores of the three time points. Mauchly's test indicated that the assumption of the sphericity had been violated; therefore, the degrees of freedom were corrected using the Greenhouse-Geisser estimates of sphericity. The partial eta-squared value was used as a measure of effect size and categorized as follows: $0.01=$ small effect, $0.06=$ medium effect, and $0.14=$ large effect (33). Post-hoc tests of differences between the three time points were analyzed using the Wilcoxon Signed Rank test. Both intention-to-treat (ITT) analyses and completecase (CC) analyses were performed when comparing scores from both patients and parents at the three assessment points. The last observation carried forward method was used when data was missing from follow-up assessment. The ITT analyses and CC analyses did not differ with regard to significance level or level of effect size. Therefore, only results from the CC analyses are reported.

\section{Results}

\section{Sample characteristics}

The number of girls was statistically significantly higher in the control group compared to the intervention group (control: $40 \%$ intervention: $13 \%, \chi^{2}[1]=23.11, \mathrm{P}<0.0001$ ) and therefore, further comparison between the control group and intervention group was divided by gender. No age differences of boys and girls were found between the two groups (Boys: intervention: mean $=15.3, \mathrm{SD}=1.8$, control: mean $=15.2, \mathrm{SD}$ $=2.6, \mathrm{Z}=-0.43, \mathrm{P}=0.67$. Girls: intervention: mean $=13.2, \mathrm{SD}$ $=1.9$, control: mean $=12.6, \mathrm{SD}=1.6, \mathrm{Z}=-1.05, \mathrm{P}=0.29$ )

A significant correlation between the patients' and the parents' rating was found for all comparable scales from CHQ-CF87 and CHQ-PF50 $(r=0.27-0.54, \mathrm{P}<0.0001$, 


\begin{tabular}{|c|c|c|c|}
\hline \multirow{2}{*}{ Domain/scale } & \multirow{2}{*}{ Description } & \multicolumn{2}{|c|}{ Scale included in } \\
\hline & & $\mathrm{CHQ}-\mathrm{CF} 87^{\mathrm{ii}}$ & CHQ-PF50 \\
\hline \multicolumn{4}{|l|}{ Health domain } \\
\hline Change in health" & Current health compared to health last year & $x$ & $x$ \\
\hline Global health" & Rating of current health & $x$ & $x$ \\
\hline General health & $\begin{array}{l}\text { The child's past, future and current health and resistance/susceptibility to } \\
\text { sickness }\end{array}$ & $\mathrm{x}$ & $\mathrm{x}$ \\
\hline \multicolumn{4}{|l|}{ Physical domain } \\
\hline Physical functioning & Presence and extent of physical limitations due to health-related problems & $\mathrm{X}$ & $\mathrm{X}$ \\
\hline $\begin{array}{l}\text { Role/social limitations- } \\
\text { physical }\end{array}$ & $\begin{array}{l}\text { Limitations in school-related activities and activities with friends due to } \\
\text { physical health }\end{array}$ & $\mathrm{X}$ & $\mathrm{X}$ \\
\hline Bodily pain & Intensity and frequency of general pain and discomfort & $\mathrm{X}$ & $x$ \\
\hline \multicolumn{4}{|l|}{ Emotional domain } \\
\hline $\begin{array}{l}\text { Role/social limitations- } \\
\text { emotional }\end{array}$ & $\begin{array}{l}\text { Limitations in school activities and activities with friends due to emotionally } \\
\text { difficulties }\end{array}$ & $\mathrm{X}$ & \\
\hline Mental health & Negative and positive states (anxiety, depression and positive affect) & $\mathrm{X}$ & $\mathrm{X}$ \\
\hline Self esteem & $\begin{array}{l}\text { Satisfaction with school and athletic ability, looks/appearances, and } \\
\text { interaction with friends/family }\end{array}$ & $x$ & $\mathrm{X}$ \\
\hline $\begin{array}{l}\text { Role/social limitations- } \\
\text { emotional and behavioral }\end{array}$ & $\begin{array}{l}\text { Limitations in school activities and }{ }^{\text {iii }} \text { activities with friends due to emotionally } \\
\text { difficulties or behavioral difficulties }\end{array}$ & & $x$ \\
\hline
\end{tabular}

\begin{tabular}{|c|c|c|c|}
\hline \multicolumn{4}{|l|}{ Behavioral domain } \\
\hline $\begin{array}{l}\text { Role/social limitations- } \\
\text { behavioral }\end{array}$ & $\begin{array}{l}\text { Limitations in school activities and activities with friends due to behavioral } \\
\text { difficulties }\end{array}$ & $x$ & \\
\hline Behavior & Behavioral problems and ability to get along with others & $\mathrm{x}$ & $\mathrm{x}$ \\
\hline Global behavior" & Behavior compared to other children at the same age & $x$ & $\mathrm{x}$ \\
\hline \multicolumn{4}{|l|}{ Family domain } \\
\hline Family activities & Limitations in family's activities due the child's behavior or health & $\mathrm{x}$ & $\mathrm{x}$ \\
\hline Family cohesion" & The family's ability to get along with one another & $x$ & $\mathrm{X}$ \\
\hline Parental impact-time & $\begin{array}{l}\text { Amount of limitations in parents' personal time due to child's physical health, } \\
\text { well-being, attention or learning abilities }\end{array}$ & & $\mathrm{x}$ \\
\hline Parental impact-emotional & $\begin{array}{l}\text { Amount of parental distress due to child's physical health, well-being, } \\
\text { attention or learning abilities }\end{array}$ & & $\mathrm{x}$ \\
\hline
\end{tabular}

$\mathrm{P}=0.006)$.

\section{Comparison of HRQL of the intervention group before surgery and the control group}

Due to the difference in gender ratios between the groups, the analyses comparing the control group and intervention group were divided by gender. As shown in Table 2, the boys in the intervention group rated their HRQL significantly lower than boys from the control group on the following subscales: physical functioning scale, role/social limitations: physical scale, self-esteem scale, and change in health scale. For the behavior scale, boys in the intervention group reported significantly higher scores compared to controls. All significant differences had small to moderate effect sizes (range: $0.25-0.72$ ). To reduce the risk of type I errors due to multiple comparisons, Bonferroni corrections were conducted, showing that the physical functioning scale and change in health scale remained statistically significant. No statistically significant differences were found between 


\begin{tabular}{|c|c|c|c|c|c|c|c|}
\hline \multirow{2}{*}{ CHQ-CF87' } & \multicolumn{2}{|c|}{ Control group } & \multicolumn{2}{|c|}{ Intervention group } & \multicolumn{3}{|c|}{ Group differences } \\
\hline & $\mathrm{n}$ & Mean (SD) & $\mathrm{n}$ & Mean (SD) & Z & $\mathrm{P}$ & d \\
\hline Physical functioning & 110 & $94.7(9.9)$ & 92 & $84.9(16.5)$ & -4.7 & $<0.0001^{*}$ & 0.72 \\
\hline Role/social: emotional & 110 & $91.5(15.8)$ & 91 & $88.4(16.5)$ & -1.4 & 0.17 & 0.13 \\
\hline Role/social: behavioral & 109 & $95.7(9.0)$ & 90 & $93.6(14.3)$ & -0.1 & 0.94 & 0.18 \\
\hline Role/social: physical & 110 & $93.9(16.5)$ & 90 & $85.8(21.9)$ & -2.8 & 0.005 & 0.42 \\
\hline Bodily pain & 110 & $73.8(22.3)$ & 91 & $67.8(23.0)$ & -2.0 & 0.05 & 0.27 \\
\hline Behavior & 110 & $82.4(10.8)$ & 92 & $86.3(8.8)$ & -2.7 & 0.007 & 0.40 \\
\hline Mental health & 110 & $81.9(12.9)$ & 89 & $80.8(12.4)$ & -0.8 & 0.40 & 0.01 \\
\hline Self-esteem & 110 & $84.1(13.3)$ & 92 & $80.8(13.7)$ & -2.1 & 0.04 & 0.25 \\
\hline General health & 110 & $77.1(14.6)$ & 92 & $79.1(14.1)$ & -1.1 & 0.29 & 0.14 \\
\hline Family activities & 110 & $84.0(16.7)$ & 90 & $86.9(15.1)$ & -1.1 & 0.26 & 0.18 \\
\hline Family cohesion & 109 & $80.0(21.6)$ & 90 & $76.1(24.9)$ & -1.1 & 0.28 & 0.17 \\
\hline Global health & 110 & $85.3(16.8)$ & 93 & $84.2(17.5)$ & -0.6 & 0.57 & 0.01 \\
\hline Global behavior & 110 & $84.7(14.6)$ & 92 & $82.0(17.9)$ & -0.9 & 0.37 & 0.17 \\
\hline Change in health & 106 & $3.7(1.1)$ & 92 & $3.3(0.9)$ & -3.2 & $0.001^{*}$ & 0.48 \\
\hline
\end{tabular}

\begin{tabular}{|c|c|c|c|c|c|c|c|}
\hline \multirow{2}{*}{ CHQ-CF87' } & \multicolumn{2}{|c|}{ Control group } & \multicolumn{2}{|c|}{ Intervention group } & \multicolumn{3}{|c|}{ Group differences } \\
\hline & $n$ & Mean (SD) & $\mathrm{n}$ & Mean (SD) & Z & $\mathrm{P}$ & d \\
\hline Role/social: emotional & 72 & $93.4(13.5)$ & 14 & $95.2(17.8)$ & -1.3 & 0.19 & 0.12 \\
\hline Role/social: behavioral & 72 & $94.3(11.9)$ & 14 & $97.6(6.4)$ & -1.0 & 0.32 & 0.35 \\
\hline Behavior & 73 & $83.4(12.3)$ & 14 & $90.1(4.7)$ & -1.7 & 0.09 & 0.73 \\
\hline Mental health & 73 & $79.3(15.0)$ & 14 & $85.3(6.1)$ & -1.2 & 0.25 & 0.52 \\
\hline Self-esteem & 73 & $84.3(13.3)$ & 14 & $87.7(9.5)$ & -0.6 & 0.53 & 0.29 \\
\hline General health & 73 & $74.5(15.7)$ & 14 & $79.9(16.1)$ & -1.3 & 0.18 & 0.34 \\
\hline Global behavior & 73 & $81.3(15.6)$ & 14 & $86.8(13.4)$ & -1.3 & 0.20 & 0.38 \\
\hline Change in health & 72 & $3.5(0.8)$ & 14 & $3.4(0.5)$ & -0.6 & 0.53 & 0.26 \\
\hline
\end{tabular}

the girls in the intervention and control groups (Table 3).

\section{Changes in HRQL scores from baseline to follow-up for the intervention group}

The patients' ratings of their HRQL at the three time points are shown in Table 4. A significant effect of time was found in 9 out of 14 of the CHQ-CF87 scales: physical functioning scale, role/social limitations: emotional, physical, behavioral scales, behavior scale, mental health scale, self-esteem scale, family activities scale, and change in health scale with a moderate-to-large range in effect 


\begin{tabular}{|c|c|c|c|c|c|c|c|c|c|c|}
\hline \multirow[b]{2}{*}{$\mathrm{CHQ}-\mathrm{CF} 87^{\mathrm{i}}$} & \multirow[b]{2}{*}{$\mathrm{n}$} & \multicolumn{3}{|c|}{ Mean (SD) } & \multicolumn{3}{|c|}{ Differences } & \multicolumn{3}{|c|}{ Post hoc tests: $\mathrm{P}^{\mathrm{ii}}$} \\
\hline & & Time 1 & Time 2 & Time 3 & $\mathrm{~F}$ & $\mathrm{P}$ & $\begin{array}{l}\text { Partial } \\
\text { eta }^{2}\end{array}$ & $\begin{array}{l}\text { Time 1- } \\
\text { time } 2\end{array}$ & $\begin{array}{l}\text { Time 1- } \\
\text { time } 3\end{array}$ & $\begin{array}{l}\text { Time } 2- \\
\text { time } 3\end{array}$ \\
\hline Physical functioning & 81 & $87.5(15.1)$ & $92.7(9.1)$ & $97.6(5.5)$ & 22.1 & $<0.0001$ & 0.22 & 0.007 & $<0.0001$ & $<0.0001$ \\
\hline Role/social: emotional & 79 & $90.6(15.8)$ & $96.5(11.9)$ & $98.7(5.0)$ & 12.8 & $<0.0001$ & 0.14 & 0.002 & $<0.0001$ & 0.31 \\
\hline Bodily pain & 81 & $71.5(20.7$ & $72.3(22.0)$ & $75.6(20.2)$ & 1.4 & 0.25 & 0.02 & 1.00 & 0.42 & 0.53 \\
\hline Behavior & 82 & $87.4(8.3)$ & $88.5(7.3)$ & $89.9(7.8)$ & 4.2 & 0.02 & 0.05 & 0.66 & 0.05 & 0.12 \\
\hline Mental health & 78 & $82.6(11.1)$ & $85.7(11.2)$ & $86.2(9.0)$ & 4.2 & 0.01 & 0.06 & 0.07 & 0.04 & 1.00 \\
\hline Self-esteem & 82 & $83.0(12.0)$ & $87.1(11.0)$ & $89.3(11.3)$ & 13.9 & $<0.0001$ & 0.14 & 0.004 & $<0.0001$ & 0.09 \\
\hline Global health & 82 & $88.2(14.0)$ & $86.0(15.3)$ & $88.0(17.8)$ & 0.8 & 0.46 & 0.01 & 0.52 & 1.00 & 1.00 \\
\hline Global behavior & 82 & $85.0(14.8)$ & $85.3(13.8)$ & $84.9(16.1)$ & 0.03 & 0.97 & 0 & 1.00 & 1.00 & 1.00 \\
\hline Change in health & 81 & $3.3(0.8)$ & $3.5(0.8)$ & $3.5(0.9)$ & 3.5 & 0.03 & 0.04 & 0.03 & 0.09 & 1.00 \\
\hline
\end{tabular}

sizes. A significant time effect was found for parents' rating of their child's HRQL in 10 out of 15 of the CHQ-PF50 scales: physical functioning scale, role/social limitationsemotional/ behavioral, physical scales, bodily pain scale, mental health scale, self-esteem scale, family activities scale, emotional impact on parents scale, family cohesion scale, and change in health scale with a moderate-to-large range in effect sizes (Table 5).

The post-hoc analysis showed that for both patients and their parents, the significant improvement of scores in the CHQ scales was primarily found from pre-surgery to follow-up. For the physical functioning scale, a significant improvement was found between each of the time points for both parents and patients.

\section{Discussion}

In this study, the patients' HRQL was evaluated prospectively using a generic measure. The patients' levels of HRQL before surgery were compared to an age-comparable control sample to assess whether they were comparable.

Before surgery, boys reported lower self-esteem, greater physical limitations and limited social activities due to health problems than did controls. However, the effect sizes were low and when the statistical significance level was adjusted for multiple comparisons, only the difference in physical functioning remained significant, with a medium effect size.

Our findings are comparable to a study by Steinmann et al. [2011] that included young adults, who also reported more physical difficulties compared to controls (7). Recent studies have shown that patients with PE have impaired cardiorespiratory function compared to control group (3-5). The impact of these reduced physiological functions is not fully established; however, they may account for the presence and extent of physical limitations reported by patients.

Previous research has shown that PE correction does have a positive impact on the patients' disease-specific HRQL $(15,18-21)$. In particular, the use of disease-specific measures increases the likelihood of showing the effect of PE correction $(22,23)$. Simultaneously however, the effect identified with disease-specific measures will not detect changes during the intervention in other areas not directly related to the disease. This may present as a potential bias in reporting, as the disease-specific measures only provide specific information about the effect of the intervention, preventing comparisons to other clinical samples or healthy peers.

In the present study, patients as well as parents reported improved emotional wellbeing and self-esteem, in addition to increased in physical and social activities at both 3 


\begin{tabular}{|c|c|c|c|c|c|c|c|c|c|c|}
\hline \multirow[b]{2}{*}{ CHQ-PF50' } & \multirow[b]{2}{*}{$\mathrm{n}$} & \multicolumn{3}{|c|}{ Mean (SD) } & \multicolumn{3}{|c|}{ Differences } & \multicolumn{3}{|c|}{ Post hoc tests: $\mathrm{P}^{\mathrm{ii}}$} \\
\hline & & Time 1 & Time 2 & Time 3 & $\mathrm{~F}$ & $\mathrm{P}$ & $\begin{array}{l}\text { Partial } \\
\text { eta }^{2}\end{array}$ & $\begin{array}{l}\text { Time 1- } \\
\text { time } 2\end{array}$ & $\begin{array}{l}\text { Time 1- } \\
\text { time } 3\end{array}$ & $\begin{array}{l}\text { Time } 2- \\
\text { time } 3\end{array}$ \\
\hline Physical functioning & 81 & $82.0(23.0)$ & $93.0(11.0)$ & $98.0(7.0)$ & 23.1 & $<0.0001$ & 0.22 & 0.001 & $<0.0001$ & 0.001 \\
\hline $\begin{array}{l}\text { Role/social: emotional and } \\
\text { behavioral }\end{array}$ & 79 & $89.6(20.0)$ & $94.8(13.2)$ & $98.5(6.6)$ & 9.6 & $<0.0001$ & 0.11 & 0.06 & 0.001 & 0.04 \\
\hline Bodily pain & 81 & $72.7(24.6)$ & $82.0(18.0)$ & $83.0(21.1)$ & 7.2 & 0.002 & 0.08 & 0.01 & 0.001 & 1.00 \\
\hline Behavior & 80 & $85.8(9.8)$ & $87.3(10.1)$ & $87.4(9.6)$ & 1.9 & 0.15 & 0.02 & 0.28 & 0.30 & 1.00 \\
\hline Mental health & 82 & $84.9(9.8)$ & $87.6(11.8)$ & $87.9(9.2)$ & 3.7 & 0.03 & 0.04 & 0.14 & 0.04 & 1.00 \\
\hline Self esteem & 82 & $77.0(14.1)$ & $80.7(14.6)$ & $83.7(16.0)$ & 7.9 & 0.001 & 0.09 & 0.05 & 0.003 & 0.18 \\
\hline Parental impact-emotional & 82 & $79.3(19.4)$ & $87.8(15.0)$ & $89.5(12.5)$ & 18.6 & $<0.0001$ & 0.19 & $<0.0001$ & $<0.0001$ & 0.79 \\
\hline Family cohesion & 82 & $79.1(18.4)$ & $82.0(15.0)$ & $84.8(12.9)$ & 4.5 & 0.02 & 0.05 & 0.33 & 0.03 & 0.30 \\
\hline Global health & 82 & $87.0(14.5)$ & $88.0(12.6)$ & $88.4(15.5)$ & 0.3 & 0.70 & 0.004 & 1.00 & 1.00 & 1.00 \\
\hline Global behavior & 81 & $88.3(12.3)$ & $88.8(13.4)$ & $90.0(13.3)$ & 0.8 & 0.45 & 0.01 & 1.00 & 0.76 & 1.00 \\
\hline Change in health & 80 & $2.4(0.8)$ & $3.5(0.7)$ & $3.7(0.8)$ & 10.8 & $<0.0001$ & 0.12 & 0.28 & $<0.0001$ & 0.01 \\
\hline
\end{tabular}

', Child Health Questionnaire-Parent Form; i , adjusted for multiple comparisons using Bonferroni correction.

and 6 months postoperatively on a generic HRQL measure. Thus, along with previous prospective studies (15,18-21), this study highlights the positive effects that the $\mathrm{PE}$ correction can have on the patients and their families. The parents reported a reduction in their own level of distress due to the child's condition as well as increased family cohesion following surgery.

There is a strong association between the ratings of HRQL by the patient and their parent, and both informants reported improvement in the same HRQL domains postoperatively. Interestingly, however, while the parents rated a reduction in frequency and intensity of their child's pain after the surgery, this was not supported by their child's own rating. Due to the subjective nature of pain, it is difficult to obtain a valid proxy-reported pain assessment (34). From the age of 5 years, children with a normal intellectual development have been shown to be capable of assessing their own pain level (35), and self-reported pain assessment by the child is therefore preferred over proxy-reported pain assessment.

It should be noted that patients reported an improvement in their behavior, which was not noticed by their parents. This difference may be due to the design of the behavior scale in the CHQ-PF50 compared to the behavior scale in the CHQ-CF87. In the parent form, the behavior scale has fewer items and all included items are related to behavior linked to more severe conduct problems. A low proxyreported score on the behavior scale will reflect severe problematic behavior, which is not present in the majority of children. Therefore, most parents assessed their child's behavior to be non-problematic. The child form, on the other hand, includes items related to more common problematic behaviors. Therefore, compared to the child's self-report, parents may tend to rate the child's behavior as less problematic and more positively on the behavior scale. This makes behavioral improvements difficult to detect, when the baseline scores are close to the ceiling of the scale. In a previous study, we found the same pattern, where parents scored their child higher on the behavior scale compared to the child's self-reported score (17).

Both patients and parents reported a significant improvement in the patient's physical function at each time point after the correction. The influence of these postoperative physiological improvements on the patient's everyday life was not established. A study by O'Keefe et al. [2013] investigating cardiopulmonary effect of PE correction showed that the improvement in appearance and self-perceived well being was found to have a greater impact 
compared to the improvement in pulmonary and aerobic exercise function (36).

The improvement of the patients' HRQL after surgery highlights the psychological implications of the deformity. However, after Bonferroni corrections, the patients' presurgical HRQL was comparable to that of their peers on all other aspects of HRQL than physical functioning. This is in accordance with the study by Steinmann et al. (2011) in which no difference was found between young adults with $\mathrm{PE}$ and controls with regard to mental quality of life domains (7). Thus, compared to healthy peers, the generic HRQL of patients before surgery does not seem to be affected, and therefore low level of HRQL, as defined by the domains in generic measures, can be questioned as an argument for correction. More studies addressing the presurgical wellbeing of the patients compared to peers are necessary to establish the impact of the deformity on the patients' wellbeing.

Before correction of the PE, patients mainly complained about the cosmetic aspect of the deformity and major concerns with body image (13). Body image was not included as a separate measure in our study, but was included as an item in the self-esteem scale along with other items not related to body image perception. As stated previously, the self-esteem scale did not differ across the groups in our study. However, due to the diversity of items in the self-esteem scale, the scale is only partially related to body image perception and a difference in some of the items included in the scale may not be detectable when looking at the whole scale. Body image has been found to be highly disturbed in patients with $\mathrm{PE}$ compared to controls in a previous study (7). It is hypothesized that an improvement in body image is related to an improvement in HRQL following surgery (24). We recommend that future studies include specific body-image measures to assess the patient's perception of his/her body image prior to surgery, and examine the link between body image and HRQL in order to determine which factor may contribute to improved HRQL after surgery.

The present study has several limitations. Firstly, the gender distribution was mostly male-dominated. There were only a few girls in the intervention group, and this may have affected the ability to detect statistically significant differences between girls in the intervention group versus controls. Secondly, approximately two thirds of all eligible patients participated in the study. This moderate response rate may have had an impact on the generalizability of the results to all patients who underwent surgery for PE at the hospital. Furthermore, one fifth of the participants included at baseline failed to return the questionnaires at the followup assessments. However, the results from the ITT analysis did not differ from the CC analysis, indicating that the missing data did not have a significant impact on the results of the study. Thirdly, the control sample only assessed their HRQL on one occasion. A follow-up assessment in the control group would have provided greater information on the stability of HRQL in adolescents as well as the testretest reliability of the measure. Test-retest analysis has only been conducted in a few samples using the CHQ. For the CHQ-PF50 and the CHQ-CF87, the test-retest showed few scales with low reproducibility $(28,37,38)$ but the average retest score for the CHQ-CF87 was higher for five scales (28), indicating that some of the improvements in the CHQ scores in the intervention group may be due to measurement error. Furthermore, in a previous study, which included this control group, patients reported higher HRQL on all parameters after the surgery (17). This is incongruous with another study comparing patients after $\mathrm{PE}$ correction with norm samples (24). These results question the representation of the control sample included in this study. However, a descriptive comparison of the child-reported control group data from this study with norm samples did not suggest a deviation from the norm $(28,30)$. Finally, the control group was comparable to the intervention group regarding the age-range for both genders. However, due to the size of the groups, it was not possible to have a matched case-control design based on the participant's age and gender, which would have been ideal.

To the best of our knowledge, this study is the first to investigate the effect of the PE correction on the patients' HRQL using generic measures, and to compare the presurgery HRQL with controls in a sample of adolescents. The improvement of both physical and psychosocial HRQL reported by both patients and their parents as proxy emphasized the psychological implications of the deformity. Even though there were few pre-surgery differences between patients and controls, the improvements of the patients' HRQL after the correction may justify the correction. The effect of the deformity on patients' wellbeing compared to controls needs to be addressed in further studies.

\section{Acknowledgements}

Funding: This work was supported by the Local Research Fund, Aarhus University Hospital, Denmark, and Biomet 
Microfixation, USA.

\section{Footnote}

Conflicts of Interest: HP is a consultant at Biomet. The other authors have no conflicts of interest to declare.

\section{References}

1. Fokin AA, Steuerwald NM, Ahrens WA, et al. Anatomical, histologic, and genetic characteristics of congenital chest wall deformities. Semin Thorac Cardiovasc Surg 2009;21:44-57.

2. Goretsky MJ, Kelly RE Jr, Croitoru D, et al. Chest wall anomalies: pectus excavatum and pectus carinatum. Adolesc Med Clin 2004;15:455-71.

3. Rowland T, Moriarty K, Banever G. Effect of pectus excavatum deformity on cardiorespiratory fitness in adolescent boys. Arch Pediatr Adolesc Med 2005;159:1069-73.

4. Lesbo M, Tang M, Nielsen HH, et al. Compromised cardiac function in exercising teenagers with pectus excavatum. Interact Cardiovasc Thorac Surg 2011;13:377-80.

5. Redlinger RE Jr, Kelly RE, Nuss D, et al. Regional chest wall motion dysfunction in patients with pectus excavatum demonstrated via optoelectronic plethysmography. J Pediatr Surg 2011;46:1172-6.

6. Jaroszewski D, Notrica D, McMahon L, et al. Current management of pectus excavatum: a review and update of therapy and treatment recommendations. J Am Board Fam Med 2010;23:230-9.

7. Steinmann C, Krille S, Mueller A, et al. Pectus excavatum and pectus carinatum patients suffer from lower quality of life and impaired body image: a control group comparison of psychological characteristics prior to surgical correction. Eur J Cardiothorac Surg 2011;40:1138-45.

8. Neviere R, Montaigne D, Benhamed L, et al. Cardiopulmonary response following surgical repair of pectus excavatum in adult patients. Eur J Cardiothorac Surg 2011;40:e77-82.

9. Tang M, Nielsen HH, Lesbo M, et al. Improved cardiopulmonary exercise function after modified Nuss operation for pectus excavatum. Eur J Cardiothorac Surg 2012;41:1063-7.

10. Maagaard $M$, Tang $M$, Ringgaard S, et al. Normalized cardiopulmonary exercise function in patients with pectus excavatum three years after operation. Ann Thorac Surg
2013;96:272-8.

11. Redlinger RE Jr, Wootton A, Kelly RE, et al. Optoelectronic plethysmography demonstrates abrogation of regional chest wall motion dysfunction in patients with pectus excavatum after Nuss repair. J Pediatr Surg 2012;47:160-4.

12. Kelly RE Jr, Mellins RB, Shamberger RC, et al. Multicenter study of pectus excavatum, final report: complications, static/exercise pulmonary function, and anatomic outcomes. J Am Coll Surg 2013;217:1080-9.

13. Krasopoulos G, Goldstraw P. Minimally invasive repair of pectus excavatum deformity. Eur J Cardiothorac Surg 2011;39:149-58.

14. Roberts J, Hayashi A, Anderson JO, et al. Quality of life of patients who have undergone the Nuss procedure for pectus excavatum: Preliminary findings. J Pediatr Surg 2003;38:779-83.

15. Lawson ML, Cash TF, Akers R, et al. A pilot study of the impact of surgical repair on disease-specific quality of life among patients with pectus excavatum. J Pediatr Surg 2003;38:916-8.

16. Krasopoulos G, Dusmet M, Ladas G, et al. Nuss procedure improves the quality of life in young male adults with pectus excavatum deformity. Eur J Cardiothorac Surg 2006;29:1-5.

17. Jacobsen EB, Thastum M, Jeppesen JH, et al. Healthrelated quality of life in children and adolescents undergoing surgery for pectus excavatum. Eur J Pediatr Surg 2010;20:85-91.

18. Kelly RE Jr, Cash TF, Shamberger RC, et al. Surgical repair of pectus excavatum markedly improves body image and perceived ability for physical activity: multicenter study. Pediatrics 2008;122:1218-22.

19. Kim HK, Shim JH, Choi KS, et al. The quality of life after bar removal in patients after the nuss procedure for pectus excavatum. World J Surg 2011;35:1656-61.

20. Hadolt B, Wallisch A, Egger JW, et al. Body-image, selfconcept and mental exposure in patients with pectus excavatum. Pediatr Surg Int 2011;27:665-70.

21. Kuru P, Bostanci K, Ermerak NO, et al. Quality of life improves after minimally invasive repair of pectus excavatum. Asian Cardiovasc Thorac Ann 2015;23:302-7.

22. Solans M, Pane S, Estrada MD, et al. Health-related quality of life measurement in children and adolescents: a systematic review of generic and disease-specific instruments. Value Health 2008;11:742-64.

23. Raat H, Mohangoo AD, Grootenhuis MA. Pediatric health-related quality of life questionnaires in clinical 
trials. Curr Opin Allergy Clin Immunol 2006;6:180-5.

24. Lam MW, Klassen AF, Montgomery CJ, et al. Quality-oflife outcomes after surgical correction of pectus excavatum: a comparison of the Ravitch and Nuss procedures. J Pediatr Surg 2008;43:819-25.

25. Nuss D, Kelly RE Jr, Croitoru DP, et al. A 10-year review of a minimally invasive technique for the correction of pectus excavatum. J Pediatr Surg 1998;33:545-52.

26. Nuss D, Kelly RE Jr. Indications and technique of Nuss procedure for pectus excavatum. Thorac Surg Clin 2010;20:583-97.

27. Landgraf JM, Ware JE. Child Health Questionnaire (CHQ): A User's Manual. Boston: The Health Institute, New England Medical Center; 1996. Available online: https://www.healthactchq.com/survey/chq

28. Raat H, Landgraf JM, Bonsel GJ, et al. Reliability and validity of the child health questionnaire-child form (CHQ-CF87) in a Dutch adolescent population. Qual Life Res 2002;11:575-81.

29. Waters E, Salmon L, Wake M. The parent-form Child Health Questionnaire in Australia: comparison of reliability, validity, structure, and norms. J Pediatr Psychol 2000;25:381-91.

30. Waters EB, Salmon LA, Wake M, et al. The health and well-being of adolescents: a school-based population study of the self-report Child Health Questionnaire. J Adolesc Health 2001;29:140-9.

Cite this article as: Lomholt JJ, Jacobsen EB, Thastum M, Pilegaard H. A prospective study of quality of life in youths after pectus excavatum correction. Ann Cardiothorac Surg 2016;5(5):456-465. doi: 10.21037/acs.2016.08.02
31. Drotar D, Schwartz L, Palermo TM, et al. Factor structure of the child health questionnaire-parent form in pediatric populations. J Pediatr Psychol 2006;31:127-38.

32. Nielsen S, Ruperto N, Herlin T, et al. The Danish version of the Childhood Health Assessment Questionnaire (CHAQ) and the Child Health Questionnaire (CHQ). Clin Exp Rheumatol 2001;19:S50-4.

33. Cohen J. Statistical Power Analysis for the Behavioral Sciences (2nd Edition). Hillsdale, NJ: Lawrence Erlbaum Associates; 1988.

34. IASP Task Force on Taxonomy. Classification of Chronic Pain. 2nd (revised) ed. Seattle: IASP Press; 2011.

35. McGrath PJ, Walco GA, Turk DC, et al. Core outcome domains and measures for pediatric acute and chronic/recurrent pain clinical trials: PedIMMPACT recommendations. J Pain 2008;9:771-83.

36. O'Keefe J, Byrne R, Montgomery M, et al. Longer term effects of closed repair of pectus excavatum on cardiopulmonary status. J Pediatr Surg 2013;48:1049-54.

37. Asmussen L, Olson LM, Grant EN, et al. Use of the child health questionnaire in a sample of moderate and lowincome inner-city children with asthma. Am J Respir Crit Care Med 2000;162:1215-21.

38. Raat H, Bonsel GJ, Essink-Bot ML, et al. Reliability and validity of comprehensive health status measures in children: The Child Health Questionnaire in relation to the Health Utilities Index. J Clin Epidemiol 2002;55:67-76. 